\title{
A combined index to classify prognostic comorbidity in candidates for radical prostatectomy
}

Michael Froehner ${ }^{1 *}$, Anna-Elisa Kellner ${ }^{1}$, Rainer Koch², Gustavo B Baretton ${ }^{3}$, Oliver W Hakenberg ${ }^{4}$ and Manfred P Wirth ${ }^{1}$

\begin{abstract}
Background: In patients with early prostate cancer, stratification by comorbidity could be of importance in clinical decision making as well as in characterizing patients enrolled into clinical trials. In this study, we investigated several comorbidity classifications as predictors of overall mortality after radical prostatectomy, searching for measures providing complementary prognostic information which could be combined into a single score.
\end{abstract}

Methods: The study sample consisted of 2205 consecutive patients selected for radical prostatectomy with a mean age of 64 years and a mean follow-up of 9.2 years (median: 8.6). Seventy-four patients with incomplete tumor-related data were excluded. In addition to age and tumor-related parameters, six comorbidity classifications and the body mass index were assessed as possible predictors of overall mortality. Kaplan-Meier curves and Mantel-Haenszel hazard ratios were used for univariate analysis. The impact of different causes of death was analyzed by competing risk analysis. Cox proportional hazard models were calculated to analyze combined effects of variables.

Results: Age, Gleason score, tumor stage, Charlson score, American Society of Anesthesiologists (ASA) physical status class and body mass index were identified a significant predictors of overall mortality in the multivariate analysis regardless whether two-sided and three-sided stratifications were used. Competing risk analysis revealed that the excess mortality in patients with a body mass index of $30 \mathrm{~kg} / \mathrm{m}^{2}$ or higher was attributable to competing mortality including second cancers, but not to prostate cancer mortality.

Conclusion: Stratifying patients by a combined consideration of the comorbidity measures Charlson score, ASA classification and body mass index may assist clinical decision making in elderly candidates for radical prostatectomy.

Keywords: Prostate cancer, Radical prostatectomy, Comorbidity, Overall survival, Competing mortality, ASA classification, Charlson score, Body mass index, Cox proportional hazard models

\section{Background}

Because of the usually slow disease progression and the competing curative treatment options with different impacts on quality of life, comorbidity is of particular clinical importance in men with early prostate cancer $[1,2]$. There is, however, no consensus on the best comorbidity classification to use in this situation [3-5]. The Charlson score [6] has probably been most extensively studied $[4,5,7]$. In addition, a multitude of other assessment instruments have been evaluated with, however,

\footnotetext{
*Correspondence: Michael.Froehner@uniklinikum-dresden.de

'Departments of Urology, University Hospital "Carl Gustav Carus", Technische Universität Dresden, Dresden, Fetscherstrasse 74, D-01307 Dresden, Germany

Full list of author information is available at the end of the article
}

inconclusive results $[3,5]$. The complementary prognostic value of different comorbidity classifications has - to our knowledge - not been demonstrated yet in patients with early prostate cancer. Stratifying by comorbidity would be important in clinical decision making as well as in the characterization of patients enrolled into clinical trials. In this study, we investigated several comorbidity classifications as predictors of overall mortality after radical prostatectomy, searching for measures providing complementary prognostic information which could be combined into a single score.

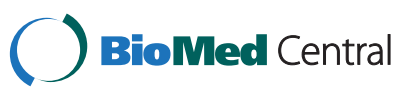




\section{Methods}

\section{Study sample}

The study sample consisted of all 2205 patients who underwent radical prostatectomy between December 1st, 1992 and December 31st, 2005 at our institution (a university hospital). Approval by the institutional review board of the University Hospital Dresden was obtained (approval reference: EK 268092009). Seventy-four patients with missing data on Gleason score, local tumor stage or lymph node status were excluded thus leaving 2131 patients for analysis. Further demographic data is given in Tables 1 and 2.

\section{Investigated variables}

Prostate-specific antigen (PSA), Gleason score, tumor stage, Charlson score [6], American Society of Anesthesiologists (ASA) physical status class [8], New York Heart Association (NYHA) class of cardiac insufficiency [9], Canadian Cardiovascular Society (CCS) class of angina pectoris [10], number of concomitant diseases (disease count), diabetes mellitus, and body mass index were investigated as categorical variables. Age was treated as a continuous variable. Patients with neoadjuvant treatment and, therefore, uncertain preoperative PSA values were included in the highest PSA risk groups.

\section{Data collection}

Data was obtained from the patient records. The specimens of patients who underwent surgery prior to 1999 were reclassified in order to ascertain data uniformity. Perioperative cardiopulmonary risk assessment (ASA, NYHA, CCS) classifications were derived from the anesthesiology premedication records. In cases with obviously incorrect classifications these were corrected under the surveillance of a senior anesthesiologist before being entered into a database.

The Charlson score was assigned based on the comorbidity data available in the database supplemented by information derived from the discharge letters largely following the original description of this comorbidity index [6]. The presence of diabetes mellitus with or without end organ damage was recorded separately as another comorbidity classification. Codes for each condition contributing to the Charlson score [6] were included in the database. A disease count was calculated by adding one point for any concomitant disease recorded in our database (angina pectoris, hypertension, history of throm-

Table 1 The results of the univariate analyses using two-sided stratifications

\begin{tabular}{|c|c|c|c|c|c|c|}
\hline Category & Events & Hazard ratio & $95 \% \mathrm{Cl}$ & $\mathrm{p}$ & 10-year survival & $95 \% \mathrm{Cl}$ \\
\hline $\mathrm{PSA}<10 \mathrm{ng} / \mathrm{mL}$ & $138 / 1165$ & 1 & & & $87.3 \%$ & $84.7-89.4 \%$ \\
\hline PSA $10+\mathrm{ng} / \mathrm{mL}$ or neoadjuvant therapy & $163 / 966$ & 1.18 & $0.93-1.48$ & 0.1665 & $83.5 \%$ & $80.5-86.0 \%$ \\
\hline Gleason score $<8$ & 198/1710 & 1 & & & $88.4 \%$ & $86.4-90.1 \%$ \\
\hline Gleason score 8-10 & $103 / 421$ & 3.44 & $2.55-4.66$ & $<0.0001$ & $72.5 \%$ & $66.7-77.4 \%$ \\
\hline organ confined & $168 / 1424$ & 1 & & & $88.1 \%$ & $85.9-90.0 \%$ \\
\hline non confined & 133/707 & 1.64 & $1.29-2.09$ & $<0.0001$ & $80.1 \%$ & $76.3-83.3 \%$ \\
\hline $\mathrm{pNO}$ & 248/938 & 1 & & & $87.2 \%$ & $85.2-88.9 \%$ \\
\hline pN1 & $53 / 193$ & 2.85 & $1.92-4.23$ & $<0.0001$ & $67.9 \%$ & $59.2-75.1 \%$ \\
\hline ASA 1-2 & 218/1774 & 1 & & & $87.9 \%$ & $85.9-89.6 \%$ \\
\hline ASA 3 & $83 / 357$ & 2.88 & $2.09-3.98$ & $<0.0001$ & $73.3 \%$ & $67.2-78.4 \%$ \\
\hline Charlson score 0-1 & 220/1809 & 1 & & & $87.6 \%$ & $85.7-89.4 \%$ \\
\hline Charlson score $2+$ & $81 / 322$ & 3.18 & $2.28-4.43$ & $<0.0001$ & $73.0 \%$ & $66.7-78.3 \%$ \\
\hline NYHA 0-1 & $270 / 2002$ & 1 & & & $85.8 \%$ & $83.8-87.6 \%$ \\
\hline NYHA 2+ & $31 / 129$ & 1.91 & $1.21-3.03$ & 0.0059 & $79.2 \%$ & $70.4-85.7 \%$ \\
\hline CCS 0-1 & $268 / 2015$ & 1 & & & $86.4 \%$ & $84.5-88.1 \%$ \\
\hline $\operatorname{CCS} 2+$ & $33 / 116$ & 2.85 & $1.74-4.67$ & $<0.0001$ & $71.2 \%$ & $60.7-79.4 \%$ \\
\hline Disease count 0-1 & 145/1296 & 1 & & & $89.1 \%$ & $86.8-91.0 \%$ \\
\hline Disease count $2+$ & $156 / 835$ & 1.97 & $1.55-2.49$ & $<0.0001$ & $79.7 \%$ & $76.2-82.8 \%$ \\
\hline No diabetes with end organ damage & $276 / 2034$ & 1 & & & $86.2 \%$ & $84.3-87.9 \%$ \\
\hline Diabetes with end organ damage & 25/97 & 3.19 & $1.78-5.71$ & 0.0001 & $68.3 \%$ & $55.2-78.3 \%$ \\
\hline Body mass index $<30 \mathrm{~kg} / \mathrm{m}^{2}$ & $237 / 1775$ & 1 & & & $86.4 \%$ & $84.4-88.3 \%$ \\
\hline Body mass index $30+\mathrm{kg} / \mathrm{m}^{2}$ & $64 / 356$ & 1.69 & $1.22-2.32$ & 0.0014 & $80.4 \%$ & $75.0-84.8 \%$ \\
\hline
\end{tabular}

$\mathrm{Cl}$ : confidence interval; $\mathrm{p}$ values are raw values. 
Table 2 The results of the univariate analyses using three-sided stratifications

\begin{tabular}{|c|c|c|c|c|c|c|}
\hline Category & Events & Hazard ratio & $95 \% \mathrm{Cl}$ & $\mathrm{p}^{*}$ & 10-year survival & $95 \% \mathrm{Cl}$ \\
\hline $\mathrm{PSA}<10 \mathrm{ng} / \mathrm{mL}$ & 138/1165 & 1 & & & $87.3 \%$ & $84.7-89.4 \%$ \\
\hline PSA $10-19.9$ ng/mL & $58 / 398$ & 1.03 & $0.76-1.41$ & 0.8429 & $86.0 \%$ & $81.4-89.5 \%$ \\
\hline PSA $20+\mathrm{ng} / \mathrm{mL}$ or neoadjuvant therapy & $105 / 598$ & 1.26 & $0.97-1.64$ & 0.0852 & $81.9 \%$ & $77.9-85.2 \%$ \\
\hline Gleason score $<7$ & $117 / 989$ & 1 & & & $88.8 \%$ & $86.3-90.9 \%$ \\
\hline Gleason score 7 & $81 / 721$ & 1.09 & $0.82-1.45$ & 0.5600 & $87.7 \%$ & $84.1-90.5 \%$ \\
\hline Gleason score 8-10 & $103 / 421$ & 3.19 & $2.35-4.34$ & $<0.0001$ & $72.5 \%$ & $66.7-77.4 \%$ \\
\hline organ confined, pNO & $162 / 1380$ & 1 & & & $88.3 \%$ & $86.1-90.2 \%$ \\
\hline non confined, pNO & $86 / 558$ & 1.30 & $0.99-1.70$ & 0.0637 & $84.4 \%$ & $80.4-87.7 \%$ \\
\hline pN1 & $53 / 193$ & 3.14 & $2.09-4.72$ & $<0.0001$ & $67.9 \%$ & $59.2-75.1 \%$ \\
\hline ASA 1 & $17 / 212$ & 1 & & & $92.9 \%$ & $88.0-95.9 \%$ \\
\hline ASA 2 & 201/1561 & 1.83 & $1.27-2.65$ & 0.0013 & $87.1 \%$ & $84.9-89.0 \%$ \\
\hline ASA 3 & $83 / 357$ & 3.28 & $2.18-4.91$ & $<0.0001$ & $73.3 \%$ & $67.2-78.4 \%$ \\
\hline Charlson score 0 & $146 / 1323$ & 1 & & & $89.4 \%$ & $87.3-91.2 \%$ \\
\hline Charlson score 1 & $74 / 486$ & 1.53 & $1.13-2.08$ & 0.0057 & $82.8 \%$ & $78.0-86.6 \%$ \\
\hline Charlson score 2+ & $81 / 322$ & 3.61 & $2.56-5.09$ & $<0.0001$ & $73.0 \%$ & $66.7-78.3 \%$ \\
\hline NYHA 0 & 245/1877 & 1 & & & $86.4 \%$ & $84.4-88.2 \%$ \\
\hline NYHA 1 & $25 / 125$ & 1.84 & $1.11-3.06$ & 0.0181 & $77.0 \%$ & $67.0-84.4 \%$ \\
\hline NYHA 2+ & $31 / 129$ & 2.01 & $1.26-3.22$ & 0.0034 & $79.2 \%$ & $70.4-85.7 \%$ \\
\hline $\operatorname{CCS} 0$ & 228/1804 & 1 & & & $87.2 \%$ & $85.2-89.0 \%$ \\
\hline CCS 1 & $40 / 211$ & 1.65 & $1.12-2.45$ & 0.0123 & $79.5 \%$ & $71.9-85.2 \%$ \\
\hline $\operatorname{CCS} 2+$ & $33 / 116$ & 3.11 & $1.87-5.16$ & $<0.0001$ & $71.2 \%$ & $60.7-79.4 \%$ \\
\hline Disease count 0 & $64 / 619$ & 1 & & & $91.2 \%$ & $88.2-93.4 \%$ \\
\hline Disease count 1 & $81 / 677$ & 1.25 & $0.90-1.73$ & 0.1822 & $87.2 \%$ & 83.6-90.0\% \\
\hline Disease count 2+ & $156 / 835$ & 2.00 & $1.53-2.61$ & $<0.0001$ & $79.7 \%$ & $76.2-82.8 \%$ \\
\hline No diabetes & 249/1877 & 1 & & & $86.7 \%$ & $84.7-88.4 \%$ \\
\hline Diabetes without end organ damage & $27 / 157$ & 1.47 & $0.93-2.32$ & 0.0990 & $80.0 \%$ & $70.5-86.6 \%$ \\
\hline Diabetes with end organ damage & $25 / 97$ & 3.35 & $1.86-6.04$ & 0.0001 & $68.3 \%$ & $55.2-78.3 \%$ \\
\hline Body mass index $<30 \mathrm{~kg} / \mathrm{m}^{2}$ & $237 / 1775$ & 1 & & & $86.4 \%$ & $84.4-88.3 \%$ \\
\hline Body mass index $30-34.9 \mathrm{~kg} / \mathrm{m}^{2}$ & $56 / 327$ & 1.55 & $1.11-2.16$ & 0.0094 & $81.4 \%$ & $75.8-85.8 \%$ \\
\hline Body mass index $35+\mathrm{kg} / \mathrm{m}^{2}$ & $8 / 29$ & 6.90 & $2.10-22.68$ & 0.0015 & $69.8 \%$ & $46.1-84.7 \%$ \\
\hline
\end{tabular}

*versus lowest risk category; $\mathrm{Cl}$ : confidence interval; $\mathrm{p}$ values are raw values.

bembolism, body mass index $30 \mathrm{~kg} / \mathrm{m}^{2}$ or higher, history of myocardial infarction, cardiac insufficiency, peripheral vascular disease, cerebrovascular disease, lung disease, ulcer disease, mild liver disease, diabetes mellitus, connective tissue disease, hemiplegia, moderate or severe renal disease, solid tumors, leukemia, lymphoma, moderate or severe liver disease, dementia, metastatic solid tumors). This was done regardless of the severity of each condition analogous to an approach described by Houterman and co-workers [11]. Follow-up data were collected from urologists and/or general practitioners, the patients, relatives, health insurance companies, local authorities or the local tumor register, whichever was necessary. Thereby, only one patient was lost to follow-up. Causes of death were assigned to the relevant categories by a senior urologist (MF). Prostate cancer was considered the cause of death in cases with uncontrolled disease progression. Second cancers were considered the cause of death when an uncontrolled second malignancy was present at the time of death. Deaths in the absence of uncontrolled prostate or second cancer were considered from deaths from non-cancer competing ("comorbid") causes. Deaths from accidents or suicide were considered a separate category. The cause of death was identified reliably in all deceased patients.

\section{Variables and stratifications}

Comorbidity variables were included into the analysis when they were available in our database and allowed for a stratification by the degree of severity into 3 categories 
(none, mild or severe). Two- and three-sided stratifications were investigated for each variable. The stratifications used are shown in Tables 1 and 2. Commonly used stratifications promising a maximal contrast for each parameter were chosen in order not to miss potentially relevant prognostic information.

\section{Statistical analysis}

Overall mortality was the primary study endpoint. KaplanMeier curves and Mantel-Haenszel hazard ratios were calculated. Univariate comparisons were made with the log rank test. Only parameters significantly associated with mortality in univariate analysis were used for multivariate analysis. Cox proportional hazard models were calculated to analyze combined effects of variables. Only parameters that remained significantly associated with mortality upon multivariable analysis were retained in the final models. After stratification by body mass index $\left(<30 \mathrm{~kg} / \mathrm{m}^{2}\right.$ versus higher), the contribution of different causes of death (prostate cancer: uncontrolled recurrent disease, competing causes: all causes of death other than uncontrolled recurrent prostate cancer, non-cancer competing causes: all non-cancer causes other than accidents or suicide, second cancers: all cancer deaths other than from uncontrolled recurrent prostate cancer) was determined by competing risk analysis [12]. The statistical analyses were performed with the Statistical Analysis Systems (SAS Institute, Cary, NC) statistical package.

\section{Results}

The mean age was 64.2 years. The mean follow-up in the surviving patients was 9.2 years (median: 8.6 years; interquartile range 4.3 years). Of the 2131 patients included in the analysis, 84 patients had died of prostate cancer and 227 of competing causes up to now (maximum follow-up: 19.4 years). The results of univariate analyses are shown in Table 1 (two-sided stratifications) and Table 2 (three-sided stratifications) and the optimal Cox proportional hazard models for two-sided and three-sided stratifications are shown in Table 3. In addition to patient age, tumor stage and Gleason score, the Charlson score, the ASA classification and the body mass index provided complementary information on overall survival probability in two-sided as well as in three-sided stratifications (Table 3). Competing risk analysis showed that the excess mortality in obese patients (body mass index of $30 \mathrm{mg} / \mathrm{m}^{2}$ or higher) was attributable to competing mortality. This competing mortality was attributable to non-cancer causes as well as second cancers (Figure 1). There was no detectable association between obesity and prostate cancer mortality (Figure 1). Considering patients with and without one of the risk factors Charlson score 2 or higher, the ASA class 3 or body mass index
$30 \mathrm{mg} / \mathrm{m}^{2}$ or higher, the observed survival difference was somewhat higher in patients aged 65 years or older (Figure 2). Stratifying patients by combining the three comorbidity classifications with complementary prognostic information (weighing was done by adding one for the risk classes ASA 2, Charlson score 1, body mass index $30 \mathrm{~kg} / \mathrm{m}^{2}$ or higher and two points for the risk classes ASA 3 or Charlson score 3 each patient) resulted in a wide separation of the survival curves with a relatively balanced distribution of the patients over the risk groups particularly when patients aged 65 years or older were considered (Table 4).

\section{Discussion}

Overdiagnosis and overtreatment are crucial issues in the management of early prostate cancer. Classifying comorbidity could be a strategy to tackle this problem [13]. However, so far, no consensus on the best way to measure comorbidity in men with early prostate cancer has been reached. Although the guideline of the European Association of Urology mentions the ASA classification beside the Charlson score is as a decision tool [14], to our knowledge, a complementary information content of these two classifications has not yet been demonstrated. Our analysis showed that in men who are candidates for radical prostatectomy the Charlson score, the ASA classification and the body mass index measured different aspects of the health status. Whereas the Charlson score is calculated as a sum of several prognostically relevant diseases with different weights, the ASA classification evaluates the general health status focused on the perioperative risk. Therefore, the observed complementary information content of both classifications (Table 3) was a plausible result. With the exception of the body mass index, all other comorbidity classifications used in our study were more or less related either to the ASA classification or to the Charlson score or both and for that reason did not provide significant complementary information despite a partially strong association with survival in the univariate analysis (Tables 1, 2 and 3).

The ability of a combination of prognostic tools to meaningfully stratify the relatively healthy candidates for radical prostatectomy was clearly superior to that of all investigated comorbidity assessment tools on their own. The combination of the tools resulted in higher survival differences, more balanced distribution of the patients over the risk groups and the consideration of different aspects of the health status. There is currently no other comorbidity classification that reaches overall survival differences between the best and the worst risk group up to roughly $50 \%$ (Table 4) in this long-living population. Even in the presence of serious comorbidity, the majority of men selected for radical prostatectomy survive more than 10 years after surgery [15]. With the six risk groups, a 
Table 3 Multivariate analysis: optimal Cox proportional hazard models for two-sided and three-sided stratifications

\begin{tabular}{|c|c|c|c|}
\hline \multicolumn{4}{|c|}{ Optimal model, 2-sided stratifications } \\
\hline Category & Hazard ratio & 95\% confidence interval & $p$ \\
\hline Age (per year) & 1.06 & $1.04-1.08$ & $<0.0001$ \\
\hline Gleason score 8+ & 2.25 & $1.74-2.90$ & $<0.0001$ \\
\hline pN1 & 1.70 & $1.24-2.34$ & 0.0010 \\
\hline ASA 3 & 1.58 & $1.17-2.12$ & 0.0030 \\
\hline Charlson score $2+$ & 1.71 & $1.27-2.30$ & 0.0004 \\
\hline Body mass index $30+\mathrm{kg} / \mathrm{m}^{2}$ & 1.47 & $1.10-1.95$ & 0.0080 \\
\hline \multicolumn{4}{|c|}{ Optimal model, 3-sided stratifications } \\
\hline Category & Hazard ratio & $95 \%$ confidence interval & $p$ \\
\hline Age (per year) & 1.06 & $1.03-1.08$ & $<0.0001$ \\
\hline Gleason score 7 & 1.07 & $0.80-1.43$ & 0.6641 \\
\hline Gleason score 8+ & 2.21 & $1.63-3.00$ & $<0.0001$ \\
\hline ASA 2 & 1.84 & $1.10-3.07$ & 0.0202 \\
\hline ASA 3 & 2.69 & $1.50-4.83$ & 0.0009 \\
\hline Charlson score 1 & 1.24 & $0.93-1.66$ & 0.1412 \\
\hline Charlson score $2+$ & 1.79 & $1.29-2.47$ & 0.0004 \\
\hline pT3-4 and pNO & 1.07 & $0.81-1.42$ & 0.6420 \\
\hline $\mathrm{pN1}$ & 1.85 & $1.30-2.62$ & 0.0006 \\
\hline Body mass index $30-34.9 \mathrm{~kg} / \mathrm{m}^{2}$ & 1.37 & $1.02-1.84$ & 0.0385 \\
\hline Body mass index $35+\mathrm{kg} / \mathrm{m}^{2}$ & 1.95 & $0.94-4.02$ & 0.0718 \\
\hline
\end{tabular}

Reference categories were other patients in the case of two-sided comparisons and the lowest risk category when two-sided comparisons were used.

relatively balanced distribution of patients, a dose-response relationship, considerable survival differences (Table 4) and easy applicability, this combined comorbidity assessment tool could be useful both for risk stratification in clinical trials and decision making. The combined comorbidity index may be used to counsel candidates for radical prostatectomy with low risk tumors who consider deferred curative treatment or to stratify patients enrolled into clinical trials comparing different treatment options for localized prostate cancer.

Obesity is associated with excess cardiovascular and cancer mortality [16-18]. In men with early prostate cancer, however, conflicting data have been reported about the prognostic significance of the body mass index [19,20]. In our study, we found a significant association of obesity (defined as a body mass index of $30 \mathrm{~kg} / \mathrm{m}^{2}$ or higher) with competing mortality but not with prostate cancer mortality after radical prostatectomy (Figure 1). This observation is supported by the relatively small contribution of prostate cancer to excess cancer mortality in obese men compared with that of several other neoplasms [17]. Thus, due to this association of obesity and excess competing (but not prostate cancer) mortality, the body mass index appears to be a suitable predictor of competing mortality complementary to the other comorbidity measures in candidates for radical prostatectomy.
The vast majority of patients selected for radical prostatectomy belong to the low risk group in the Charlson score (Charlson score 0: in our study 62\%; elsewhere: $73 \%$ [4]) and to the intermediate risk group in the ASA classification (ASA 2: in our study 73\%; elsewhere: $65 \%$ [21]). These imbalances limit the applicability of both classifications on their own in clinical decision making. In contrast, the combination of the Charlson score, the ASA classification and the body mass index distributed the patients in fairly balanced way over even more risk groups (Table 4). Furthermore, the combination of a fairly subjective assessment as the ASA classification with more objective instruments as the Charlson score and the body mass index compensates for the intrinsic weaknesses of each classification, i. e. the lack of recording specific comorbidities in the ASA classification and the disregard of the personal impression of the patient's health status with the Charlson score and the body mass index. The simultaneous recording of all three indicators may also allow for a solution of the problem of retrospectively determining the severity of health problems with chart review and may compensate for errors in classification. All three comorbidity measures are widely used and easily applicable, even though the assignment of the ASA class required a visit by a sufficiently experienced anesthesiologist. 

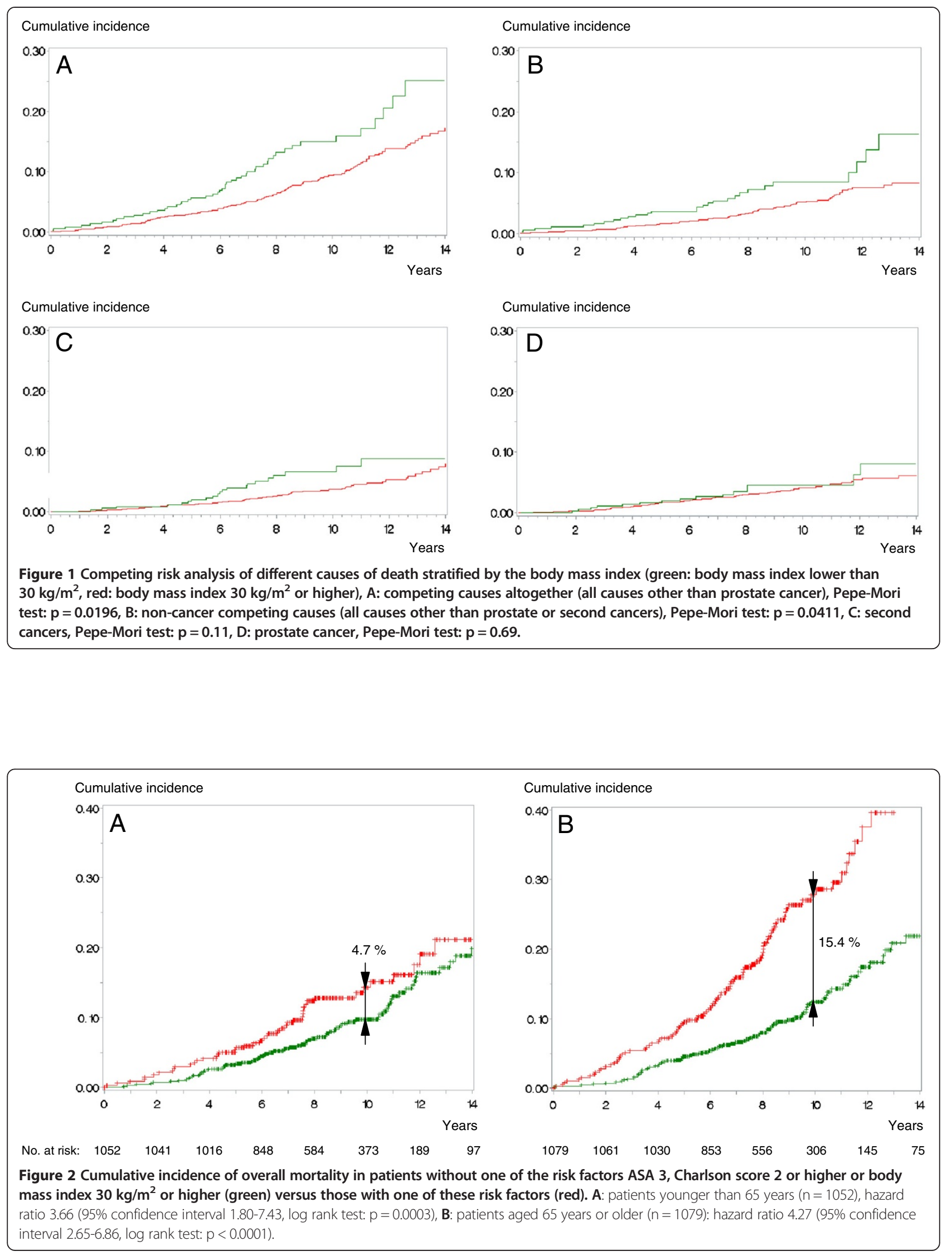
Table 4 Proportion of events, Mantel-Haenszel hazard ratios, 10-year overall survival rates, confidence intervals and $p$ values stratified by the score based on the three comorbidity classifications with complementary information content ASA class, Charlson score and body mass index in the whole sample and subdivided into age groups

\begin{tabular}{|c|c|c|c|c|c|c|}
\hline \multicolumn{7}{|c|}{ Age $<65$ years $(n=1052)$} \\
\hline Points & Events & Hazard ratio & $95 \% \mathrm{Cl}$ & $\mathbf{p}^{*}$ & 10-year survival & $95 \% \mathrm{Cl}$ \\
\hline 0 & $12 / 137$ & 1 & & & $91.5 \%$ & $84.7-95.4 \%$ \\
\hline 1 & $47 / 450$ & 1.44 & $0.81-2.56$ & 0.2133 & $90.5 \%$ & $86.7-93.3 \%$ \\
\hline 2 & $23 / 253$ & 1.30 & $0.65-2.57$ & 0.4582 & $90.9 \%$ & $85.4-94.4 \%$ \\
\hline 3 & $22 / 125$ & 2.70 & $1.35-5.39$ & 0.0049 & $80.3 \%$ & $69.6-87.6 \%$ \\
\hline 4 & $11 / 61$ & 2.68 & $1.07-6.70$ & 0.0346 & $82.5 \%$ & $69.8-90.2 \%$ \\
\hline 5 & $6 / 26$ & 7.11 & $1.73-29.24$ & 0.0066 & $74.2 \%$ & $47.2-88.8 \%$ \\
\hline \multicolumn{7}{|c|}{ Age $65+$ years $(n=1079)$} \\
\hline Points & Events & Hazard ratio & $95 \% \mathrm{Cl}$ & $\mathbf{p}^{*}$ & 10-year survival & $95 \% \mathrm{Cl}$ \\
\hline 0 & $3 / 53$ & 1 & & & $98.1 \%$ & $87.4-99.7 \%$ \\
\hline 1 & $56 / 469$ & 2.24 & $1.08-4.64$ & 0.0300 & $88.0 \%$ & $83.6-91.2 \%$ \\
\hline 2 & $46 / 259$ & 2.60 & $1.32-5.13$ & 0.0058 & $80.5 \%$ & $73.5-85.8 \%$ \\
\hline 3 & $30 / 157$ & 3.14 & $1.48-6.69$ & 0.0030 & $78.2 \%$ & $69.0-84.9 \%$ \\
\hline 4 & 29/106 & 4.07 & $1.98-8.37$ & 0.0001 & $67.0 \%$ & $54.7-76.6 \%$ \\
\hline 5 & $16 / 35$ & 21.12 & $7.45-59.90$ & $<0.0001$ & $48.9 \%$ & $26.2-68.3 \%$ \\
\hline \multicolumn{7}{|c|}{ All patients $(n=2131)$} \\
\hline Points & Events & Hazard ratio & $95 \% \mathrm{Cl}$ & $\mathbf{p}^{*}$ & 10-year survival & $95 \% \mathrm{Cl}$ \\
\hline 0 & $15 / 190$ & 1 & & & $93.4 \%$ & $88.3-96.3 \%$ \\
\hline 1 & $103 / 919$ & 1.73 & $1.11-2.69$ & 0.0149 & $89.3 \%$ & $86.5-91.5 \%$ \\
\hline 2 & $69 / 512$ & 2.00 & $1.26-3.18$ & 0.0032 & $85.7 \%$ & $81.4-89.0 \%$ \\
\hline 3 & $52 / 282$ & 2.89 & $1.77-4.71$ & $<0.0001$ & $78.9 \%$ & $72.2-84.2 \%$ \\
\hline 4 & $40 / 167$ & 3.88 & $2.25-6.70$ & $<0.0001$ & $73.0 \%$ & $64.2-80.0 \%$ \\
\hline 5 & $22 / 61$ & 21.30 & $8.95-50.72$ & $<0.0001$ & $60.3 \%$ & $43.2-73.7 \%$ \\
\hline
\end{tabular}

*versus lowest risk category; $\mathrm{Cl}$ : confidence interval; $\mathrm{p}$ values are raw values.

This study has several limitations. Although the mean follow-up was relatively long, only a small number of patients died during follow-up. It is not entirely sure that these patients are representative for the whole sample. Furthermore, patient recruitment in our study started about 20 years ago. Over that period of time, diagnostic methods, classifications and the treatment of concomitant diseases have changed and the life expectancy might have increased. A complementary prognostic impact of the ASA classification and the Charlson score has already been demonstrated for patients with bladder cancer [22,23], but not yet for patients with prostate cancer. Therefore, a confirmation and validation of our findings in different samples would be desirable. Given a sufficient sample size and follow-up, such validation would require limited effort because of the rapid accessibility of the ASA classification and the Charlson score (as well as the body mass index) during retrospective chart review. The survival rates observed in this study are only valid for the population investigated (candidates for radical prostatectomy) but not for different populations (unselected patients or patients selected for other treatment options for localized prostate cancer.

\section{Conclusion}

The three easily applicable comorbidity classifications Charlson score, ASA classification and body mass index measure different prognostic aspects of the health status in candidates for radical prostatectomy. Compared with the use of one of these three classifications on its own, the combination of the three instruments has several advantages. The combined assessment provides a more balanced distribution of patients over the risk groups, stratification into more risk groups, a greater survival difference between the best and worst risk groups and a higher resistance to classification errors by employing different and relatively independent aspects of the health status.

\section{Abbreviations}

PSA: Prostate-specific antigen; ASA: American Society of Anesthesiologists; NYHA: New York Heart Association; CCS: Canadian Cardiovascular Society;

SAS: Statistical Analysis Systems; BMI: Body mass index. 


\section{Competing interests}

The authors declare no conflicts of interest related to the matter discussed in this manuscript.

\section{Authors' contributions}

MF designed the study, collected and analysed data, wrote and drafted the manuscript, AEK collected follow-up data, RK performed the statistical analysis and drafted the manuscript, GBB contributed histopathological data, OWH drafted the manuscript, MPW provided administrative support, interpreted the data and drafted the manuscript. All authors read and approved the final manuscript.

\section{Authors' information}

MF is associate professor at the Department of Urology, AEK is medical student, RK is retired professor at the Department of Medical Informatics and Biometry, GBB is professor and chairman at the Department of Pathology of the Dresden University of Technology, OWH is professor and chairman at the Department of Urology of the University of Rostock, MPW is professor and chairman at the Department of Urology of the Dresden University of Technology.

\section{Acknowledgment}

The authors thank Bernd Garbrecht, Gert Heine, Ulrich Klenk, Rainer Litz and Caroline Menzel for their assistance in collecting clinical and follow-up data for this study.

\section{Author details}

"Departments of Urology, University Hospital "Carl Gustav Carus", Technische Universität Dresden, Dresden, Fetscherstrasse 74, D-01307 Dresden, Germany. ${ }^{2}$ Department of Medical Statistics and Biometry, University Hospital "Carl Gustav Carus", Technische Universität Dresden, Dresden, Fetscherstrasse 74, D-01307 Dresden, Germany. ${ }^{3}$ Department of Pathology, University Hospital "Carl Gustav Carus", Technische Universität Dresden, Fetscherstrasse 74, D-01307 Dresden, Germany. ${ }^{4}$ Department of Urology, University of Rostock, Ernst-Heydemann-Strasse 6, D-18055 Rostock, Germany.

Received: 12 June 2013 Accepted: 18 March 2014

Published: 29 March 2014

\section{References}

1. Read WL, Tierney RM, Page NC, Costas I, Govindan R, Spitznagel EL, Piccirillo JF: Differential prognostic impact of comorbidity. J Clin Oncol 2004, 22:3099-3103.

2. Cooperberg MR, Broering JM, Carroll PR: Time trends and local variation in primary treatment of localized prostate cancer. J Clin Oncol 2010, 28:1117-1123.

3. Alibhai SM, Leach M, Tomlinson GA, Krahn MD, Fleshner NE, Naglie G: Is there an optimal comorbidity index for prostate cancer? Cancer 2008, 112:1043-1050.

4. Guzzo TJ, Dluzniewski P, Orosco R, Platz EA, Partin AW, Han M: Prediction of mortality after radical prostatectomy by Charlson comorbidity index. Urology 2010, 76:553-557.

5. Daskivich TJ, Chamie K, Kwan L, Labo J, Dash A, Greenfield S, Litwin MS: Improved prediction of long-term, other cause mortality in men with prostate cancer. J Urol 2011, 86:1868-1873.

6. Charlson ME, Pompei P, Ales KL, MacKenzie CR: A new method of classifying prognostic comorbidity in longitudinal studies: development and validation. J Chron Dis 1987, 40:373-383.

7. Briganti A, Spahn M, Joniau S, Gontero P, Bianchi M, Kneitz B, Chun FK, Sun M, Graefen M, Abdollah F, Marchioro G, Frohneberg D, Giona S, Frea B, Karakiewicz PI, Montorsi F, Van Poppel H, Jeffrey Karnes R, European Multicenter Prostate Cancer Clinical and Translational Research Group (EMPaCT): Impact of age and comorbidities on long-term survival of patients with high-risk prostate cancer treated with radical prostatectomy: A multi-institutional competing-risks analysis. Eur Urol 2013, 63:693-701.

8. American Society of Anesthesiologists: ASA physical status classification system. Available from: http://www.asahq.org/clinical/physicalstatus.htm (accessed March 13, 2014).

9. The Criteria Committee of the New York Heart Association: Nomenclature and criteria for diagnosis of diseases of the heart and great vessels. 9th edition. Boston: Mass: Little, Brown \& Co; 1994:253-256.
10. Kaul P, Naylor CD, Armstrong PW, Mark DB, Theroux P, Dagenais GR Assessment of activity status and survival according to the Canadian Cardiovascular Society angina classification. Can J Cardiol 2009, 25:e225-e231.

11. Houterman S, Janssen-Heijnen ML, Hendrikx AJ, van den Berg HA, Coebergh $\mathrm{JW}$ : Impact of comorbidity on treatment and prognosis of prostate cancer patients: a population-based study. Crit Rev Oncol Hematol 2006, 58:60-67.

12. Pintilie M: Competing risks: a practical perspective. Chichester, England, Hoboken, NJ: John Wiley \& Sons; 2006:195-207.

13. Sandhu GS, Andriole GL: Overdiagnosis of prostate cancer. J Nat/ Cancer Inst Monogr 2012, 45:146-151.

14. Heidenreich A, Bastian PJ, Bellmunt J, Bolla M, Joniau S, Mason MD, Matveev $V$, Mottet $N$, van der Kwast TH, Wiegel T, Zattoni F: EAU guidelines on prostate cancer. Update 2013. Available from: http://www.uroweb.org/gls/ pdf/09 Prostate_Cancer_LR.pdf (accessed March 13, 2014).

15. Froehner M, Koch R, Litz RJ, Hakenberg OW, Wirth MP: Which patients are at the highest risk of dying from competing causes $\leq 10$ years after radical prostatectomy? BJU Int 2012, 110:206-210.

16. Calle EE, Rodriguez C, Walker-Thurmond K, Thun MJ: Overweight, obesity, and mortality from cancer in a prospectively studied cohort of U.S. adults. N Engl J Med 2003, 348:1625-1638.

17. Adams KF, Schatzkin A, Harris TB, Kipnis V, Mouw T, Ballard-Barbash R, Hollenbeck A, Leitzmann MF: Overweight, obesity, and mortality in a large prospective cohort of persons 50 to 71 years old. N Engl J Med 2006, 355:763-778.

18. Flegal KM, Kit BK, Orpana H, Graubard BI: Association of all-cause mortality with overweight and obesity using standard body mass index categories: a systematic review and meta-analysis. JAMA 2013, 309:71-82.

19. Siddiqui SA, Inman BA, Sengupta S, Slezak JM, Bergstralh EJ, Leibovich BC, Zincke $\mathrm{H}$, Blute $\mathrm{ML}$ : Obesity and survival after radical prostatectomy: a 10-year prospective cohort study. Cancer 2006, 107:521-529.

20. Nguyen PL, Chen MH, Beard CJ, Suh WW, Choueiri TK, Efstathiou JA, Hoffman KE, Loffredo M, Kantoff PW, D'Amico AV: Comorbidity, body mass index, and age and the risk of nonprostate-cancer-specific mortality after a postradiation prostate-specific antigen recurrence. Cancer 2010, 116:610-615.

21. Capitanio U, Pellucchi F, Gallina A, Briganti A, Suardi N, Salonia A, Abdollah F, Di Trapani E, Jeldres C, Cestari A, Karakiewicz Pl, Montorsi F: How can we predict lymphorrhoea and clinically significant lymphocoeles after radical prostatectomy and pelvic lymphadenectomy? Clinical implications. BJU Int 2011, 107:1095-1101.

22. Froehner M, Koch R, Wirth MP: Re: Mayr R, May M, Martini T, Lodde M Comploj E, Pycha A, Strobel J, Denzinger S, Otto W, Wieland W, Burger M, Fritsche HM: Comorbidity and performance indices as predictors of cancer-independent mortality but not of cancer-specific mortality after radical cystectomy for urothelial carcinoma of the bladder. Eur Urol 2013, 62:662-70. Eur Urol 2013, 63: e9.

23. Boorjian SA, Kim SP, Tollefson MK, Carrasco A, Cheville JC, Thompson RH, Thapa P, Frank I: Comparative performance of comorbidity indices for estimating perioperative and 5-Year all-cause mortality following radical cystectomy for bladder cancer. J Urol 2013, 190:55-60.

\section{doi:10.1186/1471-2490-14-28}

Cite this article as: Froehner et al:: A combined index to classify prognostic comorbidity in candidates for radical prostatectomy. $B M C$ Urology 2014 14:28. 